\title{
The happiness of people with a mental disorder in modern society
}

\author{
Ad Bergsma* and Ruut Veenhoven
}

\author{
* Correspondence: bergsma@fsw. \\ eur.nl \\ Faculty of Social Sciences, Erasmus \\ University Rotterdam, P.O. Box \\ 1738, 3000 DR Rotterdam, The \\ Netherlands
}

\begin{abstract}
Richard Layard (2005) holds modern society responsible for an 'epidemic of mental disorder', which he sees as a major source of contemporary unhappiness. Yet average happiness is high in modern society and most people with a mental disorder feel happy most of the time. This appears in an analysis of a representative sample $(\mathrm{N}=7,076)$ of the general population in The Netherlands that was screened for mental disorders. Happiness was measured using a single question on how often respondents had felt happy during the last four weeks. Of the respondents with a mental disorder 68\% reported they often felt happy during the last four weeks. People with a mental disorder may be victims of modern society, but they also benefit from modern society. Happiness is highest for people with substance abuse and anxiety disorders and uncommon for people with mood disorders.
\end{abstract}

Keywords: happiness, mental disorder, individualism, modern society

"Mental health is now our biggest social problem - bigger than unemployment and bigger than poverty," said Lord Richard Layard, in the newspaper the Guardian September 12, 2005. Layard is an emeritus professor in economics and a Downing Street advisor in the UK. He was trying to persuade the government to train an army of psychotherapists.

In his influential book 'Happiness: lessons of a new science' Layard (2005) marks mental disorder as a major source of unhappiness in modern society. For that reason he pleas for investments in curing and preventing mental disorders. Prevention should not only involve interventions at the individual level, but also social reform. In Layard's view mental disorders are part and parcel of modern market economies. He calls for taming the rat race and reducing the pressures of work, because of the 'crippling distress' involved. Layard is not the only one who holds modern society responsible for what is called the 'epidemic of mental disorders'. An early advocate of this view was Thomas Scheff (1974) and among the current supporters are reputed social scientists such as Lane (2000) and Wilkenson and Marmot (2003).

In this commentary two aspects of Layard's claims are scrutinized. Is Layard right that modern market economies are harmful for the happiness of great numbers of people? And: Are metal disorders really associated with unhappiness for all involved?

\section{Mental disorder is not the same as unhappiness}

The 'epidemic of mental disorders' is seen to occur in modern societies. Yet average happiness appears to be quite high in modern western nations. Average happiness on

(C) 2011 Bergsma and Veenhoven; licensee Springer This is an Open Access article distributed under the terms of the Creative Commons Attribution License (http://creativecommons.org/licenses/by/2.0), which permits unrestricted use, distribution, and reproduction in any medium, provided the original work is properly cited. 
scale 0-10 is 7.4 in the USA and no less than 8.4 in Denmark (Veenhoven 2010a). We now live longer and happier than ever before in human history (Veenhoven 2010b).

How can we reconcile Layard's gloomy statistics with the aforementioned high levels of happiness? Headey and Wearing (1992) show that suffering is not the opposite of happiness. They grouped people on two dimensions that are called 'well-being' and 'illbeing'. It is no surprise that a lot of people score high on well-being and low on illbeing, while a smaller group combines high ill-being with low well-being. Yet, there is also a substantive group that is not distressed, although they lack positive well-being and a group of people who are highly distressed and nevertheless experience high wellbeing.

Aspects of well-being, such as satisfaction with life, positive moods, happiness and meaning in life, appear to be closely linked and seem to have a common genetic basis (Bartels and Boomsma 2009). The same is true for aspects of ill-being. Depressive symptoms, anxiety and low moods are highly interconnected as well. However the well-being cluster only shows a moderate negative correlation with the ill-being cluster. Emotional experience can be mixed (e.g. Carstensen et al. 2000; Ersner-Hershfield 2008).

The conclusion is that we should be careful to equate mental disorders with the absence of positive well-being. This appears in the results of the Dutch NEMESIS study (Bijl, Van Zessen et al. 1998). A representative sample of 7,076 adults aged 18 to 64 years was interviewed and diagnosed for mental disorders by trained interviewers with the help of the Composite International Diagnostic Interview (CIDI) developed by the World Health Organization (Robins et al. 1988). They also answered a question on how happy they had been during the last four weeks, with response options ranging from 'never' (1) to 'continuously' (6). As expected, people diagnosed as having a mental disorder reported to have felt happy less often than those without; the average score for people with disorders being 4.1 and for people without disorders 4.9. The average difference is $18 \%$ of the scale range (Bergsma, Ten Have et al. in press).

Figure 1 shows the distribution of happy moods among people with and without mental disorder. It is apparent that the difference between the two groups is more pronounced on the negative side of the happiness continuum than on the positive side. Of the people who never or rarely felt happy during the past four weeks, $57.7 \%$ suffered from a mental disorder and an additional $26.9 \%$ had a history of a mental disorder (Bergsma, Ten Have et al. in press). We also mention lifetime prevalence because psychopathology is associated with the residual functional disability when a disorder is cured or in remission (Bijl and Ravelli 2000). Most of the very few people who are very unhappy show signs of psychopathology.

Figure 2 provides more detail about the various mental disorders involved. A first point is that people diagnosed as abusing alcohol are as happy as people without any mental disorder. This may be explained by the finding that most people abusing alcohol are young, and alcohol abuse is the only disorder that is not strongly associated with other psychiatric disorders or with functional disabilities (De Graaf et al. 2002). De Graaf et al (p. 311) conclude: "Probably we are not dealing here with psychopathology but with behavior specific to a particular phase of early adulthood, in which one sometimes is under the influence of alcohol as a result of a pleasant event." 


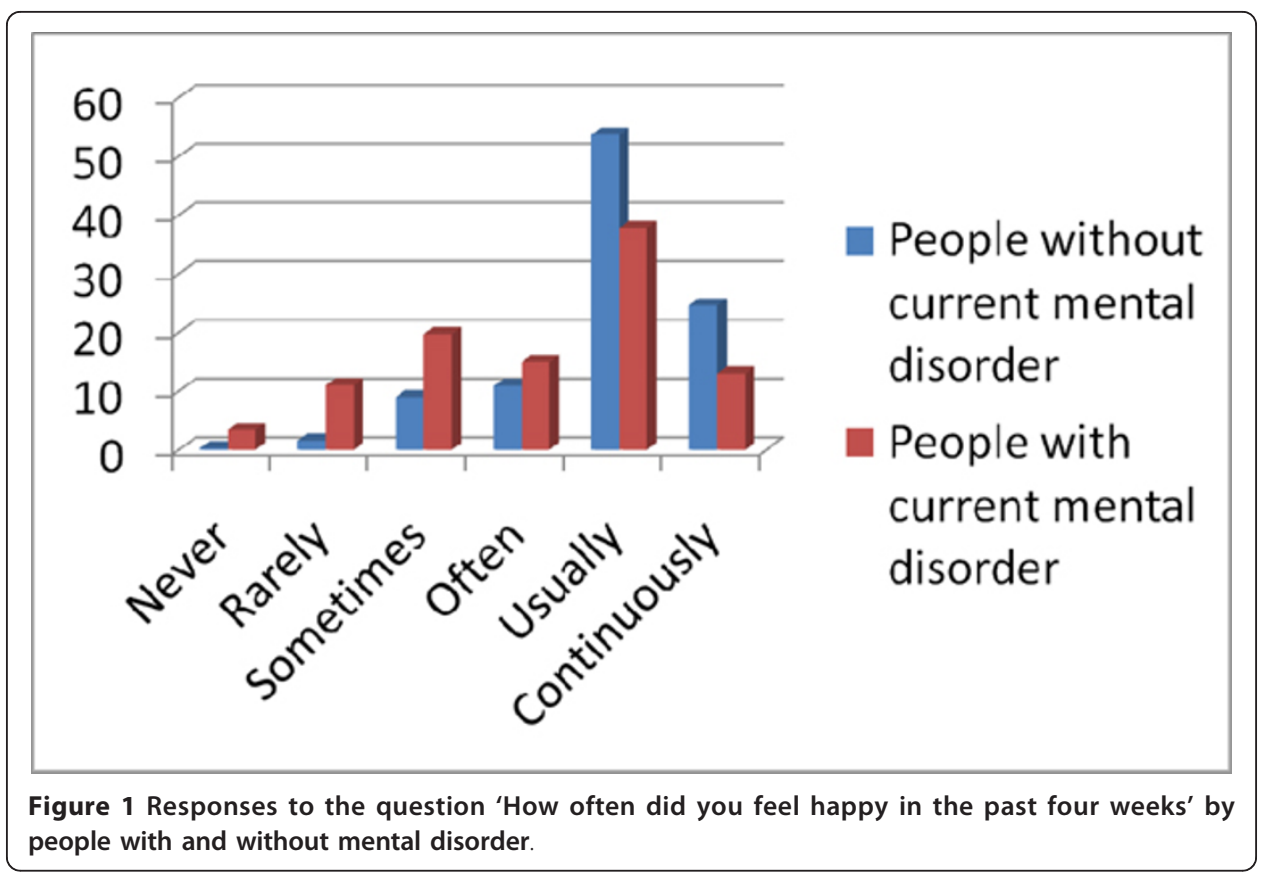

The percentage of people with anxiety disorders that feel at least often happy goes up to 80 if we exclude people with co-morbid mood disorders from our sample (Bergsma 2009). This figure is hard to align with the 'crippling distress' Layard mentions. This stern judgment should be reserved for people with mood disorders, but even in this category 30\% report having felt happy in the last four weeks and for people with an obsessive compulsive disorder (Bergsma, Ten Have et al, in press).

\section{Why are people with mental disorders happy often?}

The fact that so many depressed, anxious and addicted people feel happy often is surprising. One possible explanation is that these people were misguided or not honest about their happiness. However, the data do not support this explanation. Happiness of people with and without mental disorders turn out to be associated in the same way with other indicators of wellbeing. People with mental disorders who feel happy most of the time are less absent from work, use health care facilities less often, and use less pain medication than people with mental disorders who feel happy less often. Happy people with mental disorders also function better psychologically, are less neurotic, have better self-esteem, higher energy levels and a more relaxed attitude (Bergsma, Veenhoven et al. 2011).

This leads to a somewhat paradoxical conclusion that people with mental disorders are happy if they have the characteristics that are usually associated with good mental health. This conclusion goes well with the idea put forward by Horwitz and Wakefield (2006) that the high levels of mental disorders in the general population may be a survey artifact. A lot of people who are diagnosed as having a mental disorder, will have symptoms of mental disorders, but may still be quite able to cope, and consequently feel happy most of the time.

Our conclusion is not that the levels of distress that are signaled by the high prevalence rates of mental disorder are not to be taken seriously. It cannot be concluded 


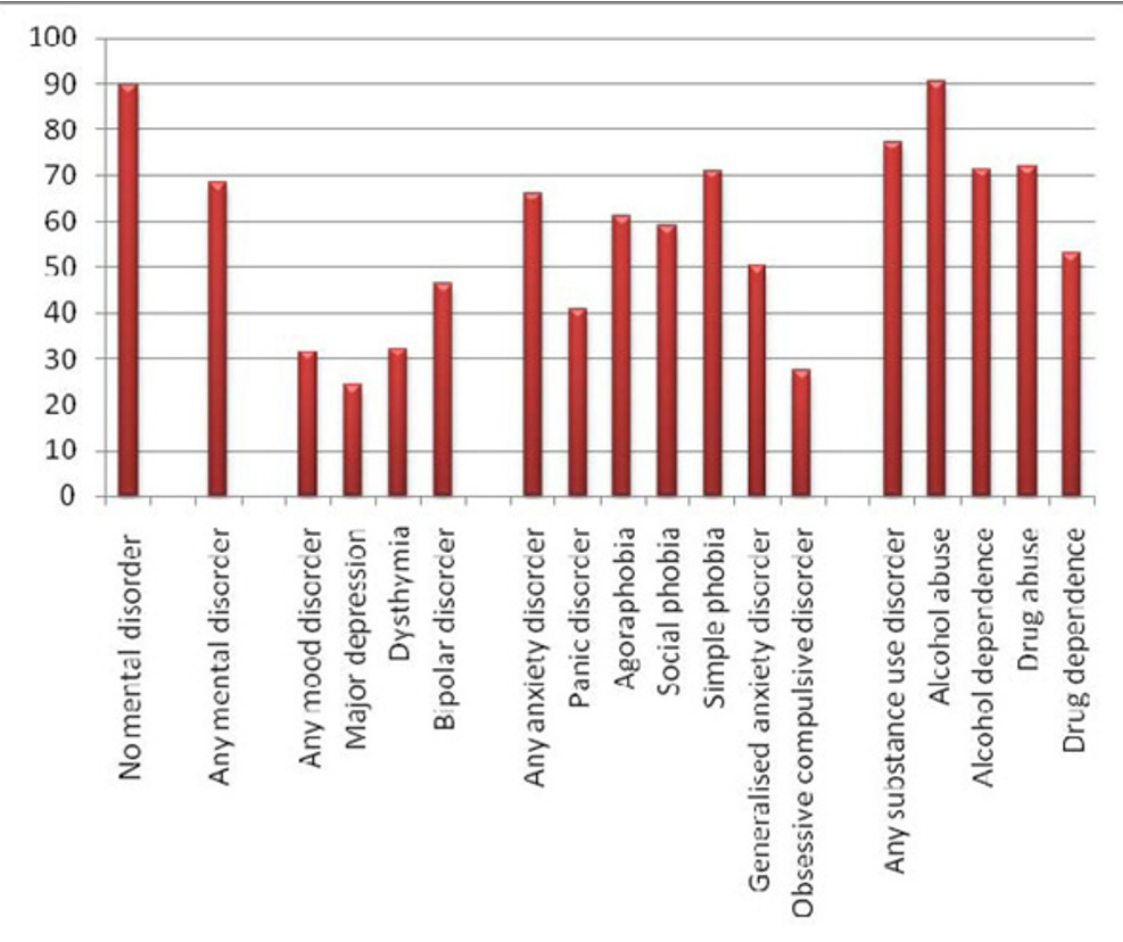

Figure 2 Percentage of people with a mental disorders that felt happy during the past four weeks.

from our data that happy people with mental disorders are actually flourishing (e.g. Deci and Ryan 2001), but we do think that the high levels of happiness reported by people with mental disorders are difficult to reconcile with the gloomy image Layard paints of modern market societies.

Layard writes about 'rampant individualism', but research shows people are happier in individualistic society (Veenhoven 1999) and one of the probable reasons is that individualism enhances the chance that one leads a life that fits one's preferences and capacities. How about the modern time stress? Research shows that people tend to be happier in countries where the pace of life is high (Garhammer 2002) and one of the reasons seems to be that such societies appeal more to the human need for challenge.

The debate whether 'epidemic of mental disorder' is a product of modern market economies is not definitively settled, but Kessler et al. (2007) found high incidences of mental disorder in non-capitalistic societies. In a large international comparison in 18 high and low income countries Bromet et al. (2011) finds that depression can be explained by personal social circumstances, such as divorce or separation form a partner, and less by macro-economic circumstances.

Even if modern society causes part of the burden of mental disorders, its victims may also still enjoy some of the concurrent benefits. Like other citizens, people with mental disorders can count on good health care, freedom of choice and the protection of the constitutional state. Layard is right that modern society has its costs that need to be addressed, but his case about the need for social reform is overstated, because he ignores the happiness for people with mental disorders. Even for people with mental 
disorders the balance between the positive and negative aspects of modern societies may be favorable.

One reason for the prominence of mental disorders in the statistics about unhappiness is that modern society has eliminated a lot of traditional sources of unhappiness, such as hunger, oppression and sexual abstinence. The better the external living conditions in society, the more the remaining differences in happiness depend on inner life ability. As a result, the negative effects of mental disorder will catch the eye more in modern society. It is possible that modern society also sets higher demands on mental health, because of its greater demands on self-direction.

\section{Conclusion}

Layard is right in that mental disorders, and especially the mood disorders, form a huge social problem that should be addressed with priority. Yet the medicine he recommends may be worse than the disease.

\section{Authors' contributions}

$A B$ is the first author of the paper and has written the first version of the article. RV has contributed to the argument and the presentation of the paper.

\section{Competing interests}

I do declare that neither me nor my coauthor have any conflicting interest in writing this paper.

Received: 14 January 2011 Accepted: 24 October 2011 Published: 24 October 2011

\section{References}

Bartels, M, \& Boomsma, DI (2009). Born to be happy? The etiology of Subjective Wellbeing. Behavior Genetics, 39(6), 605-615. Bergsma, A (2009). De meeste mensen met psychische stoornissen zijn gelukkig. Psychologie \& Gezondheid, 37, $152-161$.

Bergsma, A, Ten Have, M, Veenhoven, R, De Graaf, R (2011). Most people with mental disorders are happy; A 3-year followup in the Dutch general population. The Journal of Positive Psychology, 6, 253-259.

Bergsma, A, Veenhoven, R, Ten Have, M, De Graaf, R (2011). (online first) Do they know what they are talking about; On the value of self-rated happiness of people with a mental disorder. Journal of Happiness Studies, 12, 793-806.

Bijl, RV, Van Zessen, G, Ravelli, A, De Rijk, C, Langendoen, Y (1998). The Netherlands Mental Health Survey and Incidence Study (NEMESIS): objectives and design. Social Psychiatry Psychiatric Epidemiology, 33, 581-586.

Bijl, RV, \& Ravelli, A (2000). Current and Residual functional disability associated with psychopathology: findings from the Netherlands Mental Health Survey and Incidence Study (NEMESIS). Psychological Medicine, 30, 657-668.

Bromet, E, Andrade, LH, Hwang, I, Sampson, NA, Alonso, J, de Girolamo, G, de Graaf, R, Demyttenaere, K, Hu, C, Iwata, N, Karam, AN, Kaur, J, Kostyuchenko, S, Lepine, J, Levinson, D, Matschinger, H, Medina Mora, ME, Oakley Browne, M, PosadaVilla, J, Viana, MC, Williams, DR, Kessler, RC (2011). Cross-National Epidemiology of DSM-IV Major Depressive Episode. BMC Medicine, 9, 90

Carstensen, LL, Pasupathi, M, Mayr, U, Nesselroade, J (2000). Emotional experience in everyday life across the adult life span. Journal of Personality and Social Psychology, 79, 644-655.

De Graaf, R, Bijl, RV, Ravelli, A, Smit, F, Vollebergh, WA (2002). Predictors of first incidence of DSM-III-R psychiatric disorders in the general population: findings from the Netherlands Mental Health Survey and Incidence Study. Acta Psychiatr Scand, 106, 303-313.

Ersner-Hershfield, H, Mikels, JA, Sullivan, SJ, Carstensen, LL (2008). Poignancy: Mixed emotional experience in the face of meaningful endings. Journal of Personality and Social Psychology, 94(1), 158-167.

Garhammer, M (2002). Pace of life and enjoyment of Life. Journal of Happiness Studies, 3, 217-256.

Headey, B, \& Wearing, AJ (1992). Understanding Happiness, a theory of subjective well-being. Melbourne, Longman Cheshire. Horwitz, AV, \& Wakefield, JC (2006). The epidemic in mental illness: clinical fact of survey artefact? Contexts, 5, 19-23.

Kessler, RC, Angermeyer, M, Anthony, JC, De Graaf, R, Demyttenaere, K, Gasquet, I, De Giralamo, G, Gluzman, S, Gureje, O, Haro, JM, Kawakami, N, Karam, A, Levinson, D, Medina Mora, ME, Oakley Brown, MA, Posada-Villa, J, Stein, DJ, Adley Tsang, CH, Aguilar-Gaxiola, S, Alonso, J, Lee, S, Heeringa, S, Pennell, BE, Berglund, P, Gruber, MJ, Petukhova, M, Chatterji, S, Ustün, TB (2007). Lifetime prevelance and age-of-onset distributions of mental disorders in the World Health Organization's World Mental health Survey Initiative. World Psychiatry, 6, 168-176.

Lane, R (2000). The loss of happiness in market democracies. Yale University Press, USA.

Layard, R (2005). Happiness; Lessons from a New Science. New York: The Penguin Press.

Robins, LN, Wing, J, Wittchen, H-U, et al. (1998). The composite International Diagnostic Interview: an epidemiologic instrument suitable for use in conjunction with different diagnostic systems and in different cultures. Archives of General Psychiatry, 45, 1069-1077.

Ryan, RM, \& Deci, EL (2001). On happiness and human potentials: A review of research on hedonic and eudaimonic wellbeing. Annual Review of Psychology, 52, 141-166.

Scheff, T (1974). The labeling theory of mental illness, American Sociological Review, 39, 444-452. 
Veenhoven, R (1999). Quality-of-life in individualistic society: A comparison of 43 nations in the early 1990's. Social Indicators Research, 48, 157-186

Veenhoven, R (2010). Life is getting better: Societal evolution and fit with human nature. Social Indicators Research, 97, $105-122$.

Veenhoven, R (2010b). World Database of Happiness. Erasmus University Rotterdam http://worlddatabaseofhappiness.eur.nl/ Wilkenson, RG, \& Marmot, G (2003). Social determinants of health: solid facts. WHO http://www.euro.who.int/_data/assets/ pdf_file/0005/98438/e81384.pdf. Accessed 13 October 2011.

doi:10.1186/2211-1522-1-2

Cite this article as: Bergsma and Veenhoven: The happiness of people with a mental disorder in modern society. Psychology of Well-Being: Theory, Research and Practice 2011 1:2

\section{Submit your manuscript to a SpringerOpen ${ }^{\circ}$} journal and benefit from:

- Convenient online submission

- Rigorous peer review

- Immediate publication on acceptance

- Open access: articles freely available online

- High visibility within the field

- Retaining the copyright to your article

Submit your next manuscript at $\boldsymbol{s p r i n g e r o p e n . c o m ~}$ 